\title{
Evolución del pensamiento museológico ${ }^{1}$
}

\author{
Alfonso Castrillón Vizcarra \\ Universidad Ricardo Palma \\ ccastrillón@ @urp.edu.pe
}

\begin{abstract}
RESUMEN
Este trabajo tiene como tema la evolución del pensamiento museológico partiendo desde el coleccionismo, pasando por los especialistas o técnicos, la noción de patrimonio natural en relación a las masas del siglo XVIII-XIX. Se destaca también la labor pedagógica en los museos norteamericanos y el papel que jugó en nuestro país Julio C. Tello en relación al museo moderno peruano. Termina con la etapa de la Nueva Museología y los aportes franceses en relación al Eco museo.
\end{abstract}

Palabras clave: Pensamiento museológico, patrimonio, arte, museo, eco museo, museo peruano.

\section{The evolution of museological thinking}

\begin{abstract}
This work addresses the evolution of Museological Thinking from collecting, and going through specialists or technicians, to end with the notion of natural heritage in relation to the populations of both $18^{\text {th }}$ and $19^{\text {th }}$ century. On the other hand, the pedagogical work in the museums of North America is highlighted. In addition, the transcendental role-played by the medical doctor and anthropologist Julio César Tello Rojas in relation to Peruvian archaeology. Finally, it states the New Museology and the French contributions in relation to the Ecomuseum.
\end{abstract}

Keywords: Museological Thinking, heritage, art, museum, Ecomuseum, Peruvian museum.

1 Texto leído en ocasión de la distinción académica de Dr. Honoris Causa otorgada al autor por la Universidad Ricardo Palma el 13 de julio de 2018 
El origen de la palabra 'museo' está referido desde la antigüedad a la religión y la filosofía. En efecto, se llamaba museion al templo dedicado a las musas en las laderas de monte Helicón, en Gracia, donde se reunían los filósofos a discutir los temas más variados de su disciplina. En el bosque sagrado meditaban bajo la tutela de las nueve inspiradoras, las musas, en un ambiente académico donde todavía no se coleccionaba objetos de valor. Así pues el primigenio museion prestó más tarde su nombre a un ambiente desacralizado donde solo reinaría el arte, otra forma de sacralizar.

Estrabón (58 a.C.-25 d.C.) describe el museion fundado por Tolomeo Filadelfio (306 a.C.) como el lugar donde existía una «avenida» o peripatetos para los maestros que paseaban y dialogaban con sus discípulos (Boyance, 2002), pero en ningún momento nos habla de una colección de obras de arte. ¿Cuándo es que el templo se va convirtiendo en guardián de tesoros y de obras de arte? Me adelanto en decir que en la época de Pericles el Partenón, tenía ya una habitación independiente, a la espalda del ingreso, llamado epistodomos (Seyffert, p. 500), lugar donde se guardaba los trofeos de guerra. Más tarde, con la conquista de Grecia por los romanos, comenzaron los saqueos en tal grado que surge en Roma el mercado de arte y el coleccionismo. El historiador Suetonio nos cuenta que Julio César fue un apasionado coleccionista que donó sus esculturas al pueblo para colocarlas en un lugar simbólico y de gran tradición como el Capitolio, en Roma. (Suetonio, p. 30)

\section{Primera etapa: La tesaurización}

Durante la larga etapa que sigue desde los emperadores romanos hasta el Medioevo no primó otra práctica que la tesaurización de objetos preciosos, como camafeos, reliquias, cálices y ostensorios saqueados de iglesias y catacumbas por las huestes de turno. Se piensa que la colección no tiene otro sentido que significar el poder real y religioso. Es necesario llegar al Renacimiento para ver cómo la colección no solamente asumirá el valor estético de los objetos, sino valores históricos y científicos y dos hechos lo harán posible: la vuelta a la cultura clásica, (con la llegada del neoplatonismo y el desarrollo de la arqueología en Italia) y la riqueza acumulada en las cortes. (Brugnoli, 2010)

\section{Segunda etapa: La época de los técnicos}

Surge la necesidad de ordenar las colecciones en lugares apropiados: nace el studium, el studiolo, el cabinetto y la gallería que son los primeros e incipientes diseños museográficos. Los señores piensan que sus colecciones deberían mostrarse en público como un signo de identidad y poder, pero también para instruir, como hizo el Papa Sixto IV, Della Róvere, que restituyó al pueblo romano su colección de estatuas antiguas emplazada en el Capitolio. Fue el «Primer ejemplo de colección pública, aunque no un 
museo público, que no tuvo imitadores por mucho tiempo» (Ibídem, p. 34). Avanzado el Renacimiento entra en uso el término «museo» con una significación nueva; aparecen los eruditos, como Pablo Giovio que en 1546 crea su museo de personajes ilustres en las riberas del lago Como, al norte de Italia. O Giulio Camillo que publica "Lidea del Theatro" y expone en su museo algunas imágenes emblemáticas, pero no objetos (Ibídem, p. 53). Frente a estos ejemplos, donde se privilegia el recuerdo, surge la figura de Samuel Quiccheberg (1529-1567) que se interesa por el mundo sensible, «donde los objetos constituyen una entidad indisociable» que se piensan en función del conjunto. Se puede decir que el museo moderno nace con el pensamiento de Quiccheberg: es decir, el abandono del concepto filosófico de Museion a favor del sistema de la colección (Mairesse, 2002).

Llegados a este punto no podemos olvidar a Gaspar F. Neikel, teórico alemán que publicó el libro «Museographia» (Brugnoli, Op. cit. p. 57.) en 1727, donde aconseja la manera de exponer los objetos, las dimensiones apropiadas de las salas, la orientación de las ventanas, la luz, el color y la conservación de las obras. Fue él quien estableció las distintas tipologías expositivas: gabinetes de maravillas (Wunderkammer), gabinete de tesoros (Schatzkammer), gabinete de curiosidades (raritätenkammer), naturalienkammer (gabinete de Historia Natural) y antiquitätenkabinett (gabinetes de antigüedades) etc. Desde esa época la palabra museografía va a significar la técnica al servicio de los contenidos.

\section{Tercera etapa: Logros en medio del caos}

Así como la Revolución Francesa de 1789 operó cambios sociales indiscutibles, tuvo efectos positivos en relación al museo. Recordemos que el Museo Louvre había sido el baluarte de las artes plásticas gracias al programa de incremento de las colecciones logrado por Luis XIV y sus sucesores. En los tradicionales Salones ${ }^{2}$, sólo se permitía la entrada a los nobles, académicos y alumnos de arte. La apertura del Salón en 1793, para todos los ciudadanos, en plena época del Terror, inaugura la etapa «democrática» del Louvre bajo la dirección del pintor neoclásico J. L. David.

Podemos decir con Mairesse que si en ese momento el Louvre no era «revolucionario» a nivel museográfico, (aunque cambió su museografía abigarrada por una más holgada que hacía posible una apreciación placentera de las pinturas), ni tampoco ejemplo de buenas prácticas, el logro más significativo en ese momento fue convertirlo en el bastión del nacionalismo y de la identidad del país. (Op. cit., p. 36)

2 Exposiciones anuales que se realizaban en el Salón Cuadrado del Louvre, abiertas para el cumpleaños del monarca. 
En este sentido hay dos temas que me interesa destacar: el concepto de patrimonio nacional y cómo y por qué incluir el patrimonio del Antiguo Régimen a la cultura francesa post revolucionaria. Tratemos de explicarlo brevemente:

En 1790, en medio de la barahúnda revolucionaria se oye por primera vez la palabra "patrimonio nacional» en un pedido a la Asamblea Nacional por el ciudadano Francois Puthod de Maisonrouge. Era necesario aclarar cuál era el arte revolucionario con el que se identificaba la nueva nación: jel arte rococó del Antiguo Régimen o la pintura de David en su época revolucionaria? Naturalmente la de David que mostraba la patética imagen de Marat muerto, pero ¿qué se hacía con el resto? ¿Lo anterior a la revolución no era acaso francés? Dos problemas se presentaron a los padres de la nueva república: la más radical votaba por destruir los restos del pasado; la otra proponía vender los bienes confiscados al clero, a la corona y los emigrados. Ante la protesta de algunos intelectuales de renombre que consideraban el legado de la realeza como «una vasta y soberbia herencia», se optó por una "iconoclasia cuidadosa» (Iconoclasme soigneux) (Poulot, 2002, p. 37), que sólo tenía en cuenta los bienes superfluos. Lo que pasa en ese momento agitado es interesante: un cambio ideológico convierte por el olvido, todos aquellos signos considerados «degenerados» del Antiguo Régimen, para darles un significado universal y cosmopolita, donde se dejan de lado las diferencias étnicas e históricas. François Mairesse dice acertadamente:

El público es conducido a olvidar activamente sus antiguos temores para recordar sólo los nuevos conservados. El museo tiene la misión de construir una nación: las obras (fragmentos) deben ser sustraídas de su antiguo contexto (político-teológico), de donde viene el concepto de libertad de la obra de arte, origen de la estética moderna (Ibídem, p. 38).

Para cerrar esta etapa habría que decir que, a pesar de la política de pillaje ejercida por Napoleón en Europa y África, hay que reconocerle el mérito de haber creado los museos provinciales. Un decreto del 1 de setiembre de 1800 crea 15 museos en diferentes ciudades francesas, que en 1815 llegaron a ser 30. (Benoist, 1960)

\section{Cuarta etapa: El desarrollo del museo burgués y sus limitaciones}

«El museo es nacional, pero ante todo burgués», dice François Mairesse, y para significar cómo la ascensión de la burguesía, luego de la Revolución Francesa, va tomando un relieve importante en la industria, el comercio, los medios de comunicación, etc., bastaría citar a Baudelaire, quien exhorta a los burgueses diciendo: «Vosotros sois la mayoría —número e inteligencia—; de modo que sois la fuerza — que es la justicia» (Baudelaire, p. 476). Tampoco nos olvidemos de los reconocimientos expuestos por Marx a los lo- 
gros de la burguesía en el Manifiesto de 1848 (Marx, 1983). Se preguntarán ustedes: ¿Qué tiene que ver todo esto con el museo? El progreso que alentó la burguesía llegó también a los museos, especialmente al Louvre, que se benefició con el alumbrado, la calefacción, las técnicas museográficas, la formación de personal técnico, y sobre todo la entrada de las masas al museo, que según un hombre de letras francés, como Louis Réau, trajo algunos inconvenientes. Veamos lo que dijo en 1909:

No habría ningún inconveniente para la educación de la democracia si se separa de nuestros museos una clientela poco interesante. El Louvre está lleno durante todo el invierno de bandas de truhanes que rodean las salidas de la calefacción dando al Salón Cuadrado el aspecto de un Asilo de noche. Esto se transformaría inmediatamente si se los amenazara con el pago de un derecho de entrada. (Garland, 2002, p. 168)

Trayendo este caso al Perú, es necesario referirse a Emilio Gutiérrez de Quintanilla, Director alguna vez del Museo Nacional (1910-1917) y sus opiniones acerca de la admisión del vulgo a esa institución. Gutiérrez de Quintanilla proponía cobrar a la gente, como método de selección de los visitantes del museo:

Porque el mundo entero condena el funesto error de que el vulgo torpe y grosero se instruye, civiliza y refina contemplando de balde lo que no comprende. Ese vulgo contempla para robar, pero no para instruirse.

La instrucción es semilla que se pierde en tierra totalmente inculta...los ignorantes van a la escuela; pero a nadie se le ocurrió, ni en Europa ni en América mandarlos a los museos (1921, p. 150.).

Este pensamiento sobre el público y el museo fue felizmente rechazado y desterrado por Tello, como veremos más adelante.

\section{Quinta etapa: La labor pedagógica del museo}

Es cierto que algunos museos en Europa comenzaron a preocuparse por el público, como el caso del Museo Popular de Charles Buls, alcalde de Bruselas, entre 1860 y 1874, quien se propuso hacer llegar las ciencias y el conocimiento a las clases trabajadoras. Él pensaba que el obrero que cruzaba las salas de un museo, se sentía inundado por un respeto hacia el conocimiento de los sabios que provenía, no tanto del espacio arquitectónico, sino de los métodos de la exposición. Buls recomendaba el uso de un método escolar como "La lección de las cosas», introducido en las escuelas francesas durante la Tercera República, que consistía en despertar el interés de los niños valiéndose de objetos comunes y familiares. En el aula existía un armario-museo que los alumnos 
cuidaban y que más tarde dio origen a la maleta o museo portátil. (Demarty 1894, p. 15, en Mairesse, p. 47) Pero la verdadera preocupación por los públicos y la labor didáctica, se va a dar en los Estados Unidos de Norte América. ${ }^{3}$

El pensamiento museológico se enriqueció con el aporte de los que podríamos llamar los «primeros Museólogos» americanos como Benjamin Ives Gilman (1852-1933) , George Brown Goode (1851-1933), John Cotton Dana (1856-1929), Theodore Low (¿?), de los que podríamos decir con seguridad que su principal preocupación fue la educación del pueblo por encima de otros intereses.

Para John Cotton Dana, uno de los objetivos más importantes del museo, es mejorar la calidad de vida de la gente, centrando la atención en la comunidad y relegando la colección a simple herramienta. Esta labor se logrará gracias al equipo de trabajadores del museo, "cerebro sensible de las necesidades de la comunidad.»

Por otro lado hay que recordar que las concepciones sociales del museo ya se encontraban escritas por los fundadores del Metropolitan Museum en 1873, que en su missions statement decía que el museo debía servir principalmente a las clases trabajadoras. (Theodore Low, en Mairesse, p. 58)

La propuesta de George Brown Goode, Director del Museo de Historia Natural, es más radical todavía:

El museo del futuro, en este país democrático, se deberá adaptar a las necesidades del mecánico, del obrero de la fábrica, del jornalero, del vendedor, del empleado, así como los que ejercen las profesiones liberales o llevan una vida de ocio. (Mairesse, 2002, p. 56)

Llegados a este punto debemos abrir un paréntesis para tratar de las ideas de Julio C. Tello y su pensamiento sobre el nuevo museo entre nosotros. Sabemos de sus viajes por Europa y Norte América y cómo junto a su curiosidad científica estuvo pareja siempre la necesidad de conocer esa compleja institución que es el museo por dentro. Para esto reunió algunas publicaciones básicas como «The principles of Museum Administration» (1895) de Brown Goode, que leyó y que sin duda le sirvió como base para su estudio «Presente y futuro del Museo Nacional» (Tello y Xespe, 1967, pp. 85-94). El trabajo que Tello nombra modestamente como «informe» al Director General de Educación es, sin embargo, el primer estudio museológico importante en nuestro país, y la aplicación de las sugerencias del teórico Brown Goode se perciben sobre todo en la parte de la organización del museo, pero la originalidad se encuentra en el modo cómo Tello ha sabido aplicar los principios que rigen el museo moderno de acuerdo a las necesidades de la educación en el Perú.

3 Para lo relativo a los museos estadounidenses nos hemos basado en Mairesse, Cap. III, 53. 
Después de una introducción en la que Tello hace un rápido diagnóstico del Museo de Historia Nacional, plantea cómo debe ser el museo del futuro, suscribiendo que debe contribuir como la escuela a levantar activamente el nivel intelectual de los alumnos. Por otro lado deja muy claro que otra tarea impostergable es la investigación, pues «su reputación internacional no se basa en su edificio, sino en el número de investigadores originales que publican» (Tello, 1967, p. 87). En el informe de Tello encontramos sugerencias de tipo antropológico, arqueológico, sobre conservación, museografía, organización de personal, que no podemos analizar ahora, pero que constituyen una lectura imprescindible para los jóvenes museólogos peruanos, teniendo en cuenta que muchas ideas planteadas por el sabio arqueólogo datan del año 1913 y nos obligan a pensar si hemos avanzado desde entonces.

\section{Sexta etapa: la nueva museología}

Se puede decir que luego de la Segunda Guerra Mundial y de la fundación de la UNESCO y el ICOM, una idea es común en Europa y América: salvaguardar la democracia. Se piensa entonces que el museo puede ayudar a corregir los prejuicios y permitir una mejor comprensión entre los pueblos (Mairesse, 2002, p. 79). Se abre la época de las grandes exposiciones y el intercambio de piezas. La incipiente televisión enfrenta el objeto a la virtualidad; surge el turismo cultural; se proyectan salas permanentes y salas temporales.

Entre 1972 y 1985 se habla de "tráfico ilícito de piezas», de «restitución de bienes culturales» o de "museos y países en vía de desarrollo" y surgen los conceptos de "participación de la colectividad» $\mathrm{o}$ «identidad cultural».

Pero hay varios proyectos exitosos que abren el camino de la Nueva Museología y que es necesario apuntar, aunque someramente:

La idea de fundar un museo en el vecindario pobre de Anacostia, Washington, fue de Dillon Ripley, en 1967. Instalado en un antiguo teatro, en el corazón del barrio, no se parece en nada a los museos tradicionales porque se dirige prioritariamente a la población, a sus problemas y frustraciones. Los temas de las exposiciones tienen que ver con la búsqueda del pasado del barrio y su gente o, por ejemplo, la historia de los patriotas negros en la Independencia Norteamericana. (Mairesse, p. 100)

Otro proyecto, el Museo Nacional de Nigeria, en Niamey, fue promovido por Pablo Toucet, (1963) como resultado de la «descolonización» de las instituciones culturales africanas. Es un museo a plein air, (al aire libre), que cuenta con un jardín zoológico, un barrio de artesanos, y un pabellón para jóvenes artistas minusválidos. La experiencia de Niamey ha probado que el museo es capaz de luchar eficazmente contra las taras sociales 
como la delincuencia juvenil, la mendicidad y la ociosidad, problemas que afrontan los países africanos. (Ibídem)

Otro caso que marcó la historia de la Museología fue la Casa del Museo inaugurada por iniciativa del Museo de Antropología de México, en 1963. Mario Vázquez, entonces Director Adjunto de dicho Museo dijo: «Nos hemos olvidado de que el piso de mármol del museo es demasiado frío para los pies desnudos de sus pequeños visitantes» (Mairesse, p. 106), queriendo significar que se había pensado más en los turistas y en las clases acomodadas mexicanas y no en los campesinos ni en los habitantes de los barrios pobres. La Casa del Museo se hizo a base de módulos que se arman en cualquier sitio, al cuidado de un miembro de la comunidad. Es el lugar de encuentro de la gente del barrio, viejos y jóvenes, para hacer música, escuchar a los cuenteros o simplemente hablar de sus problemas.

No es momento de examinar qué fin tuvieron, pero sí comprobar que en ese momento crearon gran expectativa y prepararon encuentros entre especialistas como la Conferencia de Santiago de Chile, organizada por la UNESCO en 1972 y cuyo tema fue el «Papel del Museo en América Latina hoy» que tuvo gran repercusión en nuestro continente. Los expertos reunidos en ese encuentro dijeron, entre otras cosas, «Hemos sentido que los museos latinoamericanos (...) no cumplen de manera satisfactoria con su misión social que es hacer que el ciudadano se identifique con su medio natural y humano.» (Ibídem, p. 107)

Si el Estado no cumple con su papel social, el museo tiene que hacerlo: surge entonces el concepto de «Museo Integral» entendido como impulsor de la educación nacional y el desarrollo, de acuerdo a los siguientes principios divulgados en 1973, anotados por Mairesse (p. 107):

1. La técnica ha hecho progresos sorprendentes que sin embargo no han tenido eco en el mundo cultural. El desequilibrio es peligroso.

2. Esta situación no puede ser resuelta por una sola disciplina sino por conceptos interdisciplinarios.

3. El museo posee los elementos claves para promover la toma de conciencia de la comunidad frente al desequilibrio entre técnica y cultura.

El camino estaba preparado para la llegada de la Nouvel Museologie (Nueva Museología) que aparece en la década de los 80, gracias al pensamiento de Georges Henri Rivière y Hugues de Varine, miembros del ICOM. Si buscamos una primera definición tendremos que tener en cuenta que en la Nueva Museología la colección - tradicionalmente tenida como el corazón del museo- se ubica en la periferia del sistema y se reemplaza por el factor humano. Además, no se dirige al turista de paso, sino al individuo que vive sobre el territorio: es decir un museo para el hombre y su entorno natural en vista a su realización como especie. 
Fruto de las investigaciones y proyectos de Rivière en los Parques Naturales de las Landas (cerca de Burdeos) nace el «ecomuseo»:

Es un instrumento que un poder público y una población conciben, fabrican y explotan conjuntamente. (...) Es un espejo en el que esa población se mira, para reconocerse en él. (...) Un espejo que esa población presenta a sus huéspedes, para hacerse comprender mejor, en el respeto a su trabajo, sus comportamientos, su intimidad. (Rivière, 1992, pp. 191)

En el ecomuseo, las funciones del museo se ordenan de otra manera: La función de exponer, antes presente como esencial, se relega a un segundo plano. El orden de su finalidad también viene trastocado: la función de estudio prevalece sobre la conservación de los bienes y el saber reemplaza a la delectación. ¿En qué consiste el ecomuseo?

Hugues de Varine nos dice: «La comunidad toda constituye un museo viviente cuyo público se encuentra permanentemente al interior. El museo no tiene visitantes sino habitantes» (2002, p. 109) El museo no posee colecciones, aunque se pueden poner en reserva aquellas arqueológicas o muestras naturales para preservarlas. Pero todo objeto que tiene un dueńo y lo usa (por razones funcionales o sentimentales) se inventaría y queda al cuidado del poseedor. Este museo que se construye poco a poco no puede tener conservadores. Tiene actores: es decir, todos los habitantes de la comunidad.

Fruto de los estudios de Rivière, Varine y otros especialistas como Bornibus y Évrad, es el proyecto de Creusot-Montceau-Les Mines, conjunto de localidades francesas entre Dijon y Lyon, mitad rurales e industriales, de unos 500 km2 y 150,000 habitantes, dedicadas a las actividades mineras, siderúrgicas y a la manufactura de cristales. En su momento muy prósperas, había decaído notablemente a finales de los 60, por lo que constituía el terreno apropiado para un experimento suigéneris. (Rivière, Op. Cit. p. 191.) Creusot-Montceau-Les Mines es el ejemplo paradigmático del ecomuseo francés.

Es natural que a estas alturas haya surgido en ustedes la pregunta ¿y en el Perú? Nuestro "pensamiento" se puede evidenciar en dos momentos: uno que comienza en 1913, con la aparición del trabajo de J.C.Tello titulado «Presente y futuro del Museo Nacional» y otro, luego de un largo paréntesis, con la creación de ICOM Perú, el 18 de mayo de 1987, donde un grupo de amigos (entre ellos Luis Repetto Málaga) empeñaron su voluntad para sacar adelante a los museos peruanos. Desde entonces ha habido reuniones nacionales con la asistencia de connotados especialistas de los que hemos aprendido teorías y técnicas. Desde el año 1975 me encargaron el dictado del curso de Museología en Cusco, en el programa auspiciado por la Fundación Andrés Bello/OEA/ 
INC. Debo agregar que en 1986 publiqué el libro «Museo Peruano. Utopía y realidad», donde propongo el método del Diseńo Museológico como herramienta que tener en cuenta para construir un nuevo museo. La lista de museos ha crecido notablemente creando la necesidad de personal especializado.

En este sentido la Universidad Ricardo Palma dio un paso adelante a favor de la Museología en nuestro medio creando la Maestría en Museología y Gestión Cultural en 1999. En 2009 la exalumna Cecilia Meléndez Zamudio se graduó de Magister en Museología con una tesis cuyo tema era "Ecomuseo etnográfico de Jauja» y años más tarde la exalumna Mercedes Silva Osorio, fallecida prematuramente, creó el programa «Museos puertas abiertas» para Canal 7, cuyo eslogan era "Los museos están cambiando» (Recuerdo que Meche quería hacer su tesis sobre un museo virtual, tesis que se convirtió en un programa televisivo que ha tenido mucho éxito.). La Asociación de Museólogos del Perú (Anamup) se creó en 2015. En fin, podría seguir: Los datos son numerosos, los recuerdos desordenados, pero es momento de detenerse y dejar en manos de los futuros museólogos lo que quedó en el tintero, que —estoy seguro— lo harán mejor que yo.

Gracias.

Miraflores 13 de julio de 2018.

\section{Referencias}

Baudelaire, Ch. (1963) Salón de 1864, en Obras completas. Madrid, México, Buenos Aires: Editorial Aguilar.

Benoist, L. (1960). Musées et Muséologie. París: Presses Universitaires de France.

Boyance, P. (2002) Le culte des Muses chez les philosophes grecs. Étude d'histoire et de psychologie religieuses. En: Mairesse,F. Le Musée temple spectaculaire. Lyon: Presses Universitaires de Lyon PUL

Brugnoli, M. V. (2010) Dal privato al pubblico. Note sul collezionismo d'arte e di antichitá dal antico al secolo XVIII. Roma: Campisano Editore.

Clair, J. (2008) La crisi dei musei.La globalizzazione della cultura. Milano: Skira.

Gов, A. (2010) Le musée, une institution dépassée? Paris: Armand Colin.

Gutiérrez de Quintanilla, E. (1921) Memoria del Director del Museo de Historia Nacional. 1912-1921, tomo I, Lima.

Mairesse, F. (2002) Le Musée temple spectaculaire. Lyon: Presses Universitaires de Lyon

Marx, C. (1983) Manifiesto Comunista y otros ensayos. Madrid: Serpe.

Pomian, K. (2004) Dalle sacre reliquie all' arte moderna. Milano: Il Saggiatore.

Poulot, D. (2002) Musée, Nation, Patrimoine. París, Galimard, 1997. En: Mairesse, F. Le Musée temple spectaculaire. Lyon: Presses Universitaires de Lyon PUL 
Rivière, G.H. (1992) La Museología, Curso de Museologíaltextos y testimonios. Madrid: Akal. SAlmon, P. (1958) De la collection au musée, Brussels, Neuchatel: Éditions La Baconniére.

Seyffert, O. (1947) Eciclopedia Clásica, vol.II. Buenos Aires: Ed. El Ateneo.

Suetonio. (1968) Vidas de los doce Césares. En: Clásicos, vol. V. W.M. Jackson, Inc. Editores.

TAYlor, F.H. (1960) Artistas, principes y mercaderes. Historia del coleccionismo desde Ramses a Napoleon. Barcelona: Luis de Caralt.

Tello, J. C. y Mejía Xespe, T. (1967) Revista Arqueológicas, No 10, p. 85-94. 